Para enlazar con este artículo / To link to this article:

http://dx.doi.org/10.14198/fem.2017.30.09

Para citar este artículo / To cite this article:

Nicolau Jiménez, Adriana. «Aspectos de la maternidad actual en El conejito del tambor de Duracell de Marta Galán». En Eva García-Ferrón y Cristina Ros-Berenguer (coords.), Dramaturgia femenina actual. De 1986 a 2016. Feminismo/s, 30 (diciembre 2017): 169-191, DOI: 10.14198/fem.2017.30.09

\title{
ASPECTOS DE LA MATERNIDAD ACTUAL EN EL CONEJITO DEL TAMBOR DE DURACELL DE MARTA GALÁN
}

\author{
ASPECTS OF CURRENT MOTHERHOOD IN THE DURACELL'S \\ BUNNY WITH THE DRUM BY MARTA GALÁN
}

\author{
Adriana NiCOLAU JiMÉNEZ \\ Universitat Oberta de Catalunya \\ anicolauj@uoc.edu \\ orcid.org/0000-0002-1916-3200
}

\section{Resumen}

El objetivo de este artículo es estudiar la visión de la maternidad en la obra teatral El conejito del tambor de duracell de Marta Galán, así como su adaptación y puesta en escena por Marc Martínez. Nuestro estudio se basa en la lectura atenta del texto a partir de un sucinto marco teórico compuesto por aproximaciones feministas de la maternidad -esencialmente Federici, Sau, Badinter y Fernández Pujana- al cual se añade una entrevista personal a la autora. Siguiendo muy de cerca a Federici, el texto de Galán constituye un alegato a favor de la politización de los cuidados y contra la actual devaluación del trabajo reproductivo de las mujeres, bajo la supuesta solución que constituye la conciliación. La obra es sintomática de la aparición de nuevas temáticas en el mundo teatral a causa de la progresiva incorporación de las mujeres en los roles de autoría y dirección, así como su adaptación lo es de las limitaciones que aún siguen imponiendo el establishment y la omnipresente perspectiva masculina.

Palabras clave: Marta Galán, teatro, maternidad, trabajo reproductivo, Silvia Federici.

\begin{abstract}
This article's goal is to study the perspective on motherhood in Marta Galán's play The duracell's bunny with the drum, as well as its adaptation and staging by Marc Martínez. Our study is based on the text's close reading grounded on a succinct theoretical frame composed by feminist approaches on motherhood -essentially Federici, Sau, Badinter
\end{abstract}


\& Fernández Pujana- and a personal interview with the author. Strongly based on Federici's theories, Galán's text builds a claim in favour of a politicization of care, and against the current devaluation of women's reproductive work, under the supposed solution of labour and family conciliation. The play is symptomatic of the emergence of new topics in theatre due to the increasing amount of women in the role of directors and authors. Its adaptation is an example of the limitations that are still imposed by the theatrical establishment and the ubiquitous masculine perspective.

Keywords: Marta Galán, theatre, motherhood, reproductive work, Silvia Federici. 
Nuestra historia actual es la de miles de mujeres que agonizan sobre los libros, el cuadro o la canción que nunca podrán acabar o que ni siquiera pueden comenzar, porque no disponen de tiempo o dinero (Federici 2013, 99).

Marta Galán (Barcelona, 1973) es «autora y directora de proyectos escénicos desde 1999 », tal como se define en su página web personal ${ }^{1}$. Su obra se sitúa en el terreno del teatro postdramático, y propone una reflexión que oscila entre la reivindicación de corte social y la indagación existencial e identitaria. En 2015 escribe El conillet del tambor de duracell [sic] (El conejito del tambor de duracell [sic]), un solo en el que una mujer madre de dos hijos expone sus dificultades prácticas, emocionales y económicas para vivir de manera plena su propia vida, su maternidad y su relación de pareja, al tiempo que elabora una crítica muy explícita y combativa al tratamiento de la maternidad por parte de nuestra sociedad, al modelo de familia heteropatriarcal y al sistema capitalista.

En los últimos años, la progresiva incorporación de las mujeres al mundo teatral en calidad de directoras y autoras ha propiciado la aparición de un número reducido de obras que giran en torno a la maternidad ${ }^{2}$, una problemática que, como otras cuestiones tradicionalmente ligadas a la vida cotidiana de las mujeres, es extraordinariamente reciente en el ámbito del teatro. Por ello, el objeto de nuestro estudio reviste un especial interés, así como por su manera de abordar la maternidad en tanto que cuestión política, y por consiguiente afirmando la necesidad de su reconsideración en los planos político y cultural. Cabe añadir la importancia que la pieza tiene en la trayectoria de la autora, puesto que supone su acceso al gran público: el mismo año de su creación, el texto fue adaptado y dirigido por Marc Martínez y protagonizado por Clara Segura en una puesta en escena que cosechó un gran éxito de público y crítica.

1. <http://www.marta-galan.com/index.php?Mparam=bio-trayectoria>, consultado el 23-05-2017.

2. A manera de ejemplo: Fes-me una perduda, de Mercè Sàrrias, sobre el mito de la superwoman; La lista, de Jennifer Tremblay e interpretada por Laia Marull en el Lliure, sobre la carga mental de las mujeres; o, en el campo del teatro-danza, Mujer embarazada con hoja en blanco, de Constanza Brcnic. 
En este artículo estudiaremos qué concepto de la maternidad moviliza la obra y de qué forma lo articula en relación a una subjetividad a través de la cual se exponen también los sentimientos que puede generar esta experiencia. Para guiar nuestro análisis nos serviremos de una bibliografía reducida de aproximaciones feministas a la maternidad que nos permitirá abordar los aspectos esenciales del texto en relación a esta temática. Asimismo, exploraremos brevemente qué cambios se operan en la adaptación y puesta en escena realizadas por Martínez $z^{3}$.

\section{INTRODUCCIÓN AL CONCEPTO DE MATERNIDAD ACTUAL}

Piezas como la de Marta Galán reflejan la necesidad de iluminar una realidad silenciada en el ámbito de la representación a lo largo de los siglos -como señalara ya Adrienne Rich en Of Woman Born-, y traslucen al mismo tiempo un malestar contemporáneo en relación al espacio de los cuidados en nuestra sociedad. Diversas pensadoras feministas -como Silvia Federici, Elizabeth Badinter, Adrienne Rich o Victoria Sau- han demostrado que la maternidad tal y como la entendemos hoy en día es un constructo cultural producto de las sociedades patriarcales, que encuentra sus fundamentos en la ideología rousseauniana sobre los cuidados (s. XVIII) y en la separación de espacios domésticos y de producción que conllevó la propagación del sistema fabril (s. XIX). Como explica Sau, la madre ha sido tradicionalmente una «función del Padre» (32), mero vehículo para finalidades masculinas que se ha visto obligada a renunciar a sus propios intereses: «la mujer no deja de ser una mujer por el hecho de ser madre; en todo caso, ha adquirido una función más. Pero la cultura patriarcal ha convertido la palabra madre, o sea, la función, en la mujer como totalidad $[. .$.$] » (30). La idea del instinto maternal ha sido fundamental$ para mantener a las mujeres en esta función: se ha instaurado la idea de que la reproducción, «entendida como el complejo de actividades y relaciones gracias a las cuales nuestra vida y nuestra capacidad laboral se reconstruyen a diario» (Federici 2013, 21), es un «atributo natural de nuestra psique y personalidad femenina, una necesidad interna, una aspiración, proveniente supuestamente de las profundidades de nuestro carácter de mujeres» (Federici 2013, 37). Sin embargo, el hecho de que a lo largo de la historia las madres hayan maltratado, vendido, mutilado y asesinado a sus propias hijas (Sau 42), junto con «la imposibilidad de definir un comportamiento maternal propio

3. No puedo dejar de agradecer aquí la ayuda de Marta Galán, por su buena disposición y afabilidad, así como de mi directora de tesis, Teresa Iribarren, y de Joan Pujolar, Marina Massaguer, María Zaragoza y Mireia Manzano. 
de la especie humana» (Badinter 72), ponen en entredicho el concepto del instinto maternal. En la actualidad occidental, la maternidad es el espacio de la vida cotidiana que quizás evidencia de forma más fehaciente la ideología de género, puesto que se promueve un modelo ideal de madre y al mismo tiempo «se obstaculiza un desarrollo armonioso de ese ideal -ya que los cuidados no están en la centralidad del quehacer político e institucional y continúan considerándose un asunto privado de los hogares, y fundamentalmente de las mujeres» (Fernández Pujana 35-36). Además, el modelo que se impone como natural y universal es en realidad clasista y racista, puesto que está ligado a la situación concreta de mujeres blancas, occidentales y de clase media (Esteban 223, citado por Fernández Pujana 22).

\section{TRAYECTORIA DE MARTA GALÁN}

Marta Galán nace en Barcelona y, después de pasar su infancia en Madrid, regresa a la capital catalana para cursar estudios de Filología Hispánica y Artes Escénicas. En 1997 estudia dramaturgia y dirección en la EMAD (Escuela Municipal de Arte Dramático de Buenos Aires). De regreso a Barcelona, en 1998, funda la compañía La Vuelta, con Núria Lloansi, Xavi Bobés, Mireia Serra y otros, con la que estrena Lu Blanc de Lu Groc (1999), Desvínculos (2000, Sala Conservas), K.O.S. Fer-se el mort (Sitges Teatre Internacional, 2001) y Estamos un poco perplejos (Sitges Teatre Internacional, 2002), con la que la compañía se disuelve. A inicios de los años 2000 Galán comienza una nueva etapa de cocreación con el performer y cantante Santiago Maravilla, con quien produce la Trilogía Cínica, formada por Lola (La Poderosa, 2003), Machos (Escena Abierta Burgos, 2005) y El Perro (Festival Panorama de Olot, 2006); Transilvania 187, in memoriam (Ca l’Estruch en Sabadell, 2004) y Melodrama (La Fundición de Bilbao, 2007). También en cocreación, esta vez con Juan Navarro y Núria Lloansi, estrena en el ciclo Radicals Lliure del Teatre Lliure de Barcelona Protégeme, Instrúyeme (2008). A finales de la primera década del nuevo siglo, su interés deriva «a prácticas socioeducativas contextuales» (Gázquez 167): en esta línea se estrenan las Superproducciones postdramáticas de un solo uso (Dark figurantes, Reprise, Madres, tetas y nanas en la Nau Ivànow, 2009; y Morir de amor aquí, CAET de Terrassa, 2011), que involucran a varias entidades y personas de la sociedad civil. Con Morir de amor aquí, y después de años de trabajo precario y auto-gestionado, la autora siente agotarse su «deseo de hacer teatro» (Gázquez 466), lo que la llevará, junto con un traslado de Barcelona al Empordà y las necesidades derivadas de una doble maternidad, a abandonar progresivamente la actividad teatral. Así, habrá que esperar al año 
2015 para presenciar nuevamente en Barcelona uno de sus textos llevados a escena.

Según Cornago, la obra de Galán constituye, junto con las de sus compañeros de generación, el exponente de una sensibilidad del cambio de siglo fundamentada en la duda y el fin de los grandes relatos, que coincide además con un momento de precarización del mercado teatral. Estos autores -Carlos Marquerie, Angélica Liddell, Rodrigo García o la misma Galán, entre otrosproducen discursos confesionales de diversa índole, que a menudo parten del cuerpo como garantía última del yo. Por su parte, Gázquez destaca la importancia de la propia identidad para una generación de autoras españolas nacidas entre 1966 y 1978 que trabajan «con el material autobiográfico para crear piezas coreográficas donde se impone el concepto de auto-ficción» (11) Se trata de "poéticas de la experiencia y de lo personal» que se escenifican a menudo en solos, destilando materiales autobiográficos que sirven para cuestionar «el concepto de identidad» (56). Como Galán, todas ellas comienzan en proyectos grupales que abandonan a inicios del siglo XXI para emprender carreras individuales, desarrolladas mayoritariamente en circuitos alternativos. Salvo excepciones (como las de Juan Domínguez o Sergi Faüstino), estos discursos aparecen más y de manera más profunda en creaciones de autoría femenina, lo cual se debería a que «todas ellas trabajan con el cuerpo plástico y performativo, y este siempre ha sido fuente de conflicto o de exclusión» (17).

De entre todas sus compañeras de generación, destaca Gázquez, Galán es la que confiere una mayor importancia al texto -que decanta casi siempre en versículos libres-y también la que trabaja desde una posición más abiertamente política. Según Cornago, su trabajo «puede entenderse como una búsqueda de una verdad emocional a la que se acerca a la vez desde la experiencia personal y la reflexión en torno a lo social» (169). Su manera de entender la creación teatral, que se enmarca en el campo del teatro postdramático y ha tendido progresivamente hacia lo performativo, propone además «una performance de la narración permeable a la otredad del intérprete» (Gázquez 57): habitualmente, Galán presenta un texto que funciona como punto de partida y que puede modificarse y combinarse con aportaciones de los actores a través de los ensayos. Por lo tanto, sus espectáculos presentan, más que personajes, subjetividades superpuestas; y más que tramas, visiones poliédricas de una determinada problemática, generalmente de forma fragmentaria y mezclando discursos monológicos con acciones físicas, música, vídeos, etc., que

4. Dichas autoras son: «Constanza Brcnic, Paloma Calle, Amalia Fernández, Bea Fernández, Marta Galán, Sonia Gómez, Lidia González-Zoilo (Macarena Recuerda), María Jerez, Loreto Martínez Troncoso, Mònica Muntaner, Victoria Szpunberg y Ada Vilaró» (11). 
configuran una estética voluntariamente excesiva como forma de cuestionar los lenguajes teatrales miméticos.

Galán señala el feminismo como uno de sus grandes temas (Nicolau/Galán) y ha explorado cuestiones de género a lo largo de su carrera: por ejemplo, en Lola y Machos, donde se centra en la construcción hegemónica de la masculinidad; o en Morir d'amor aquí, pieza en la cual reflexiona «sobre la no operatividad del amor en contextos donde se imponen paradigmas patriarcales de violencia y dominación $»^{5}$. Madres, tetas y nanas, la tercera de sus Superproducciones, se centra en el tema de la maternidad, llevando a escena a veinte mujeres con sus respectivos bebés, a los que dan el pecho, y a un grupo de mujeres mayores que cocinan para el público. En la carta de presentación, la autora explica:

Se trata de una propuesta musical y escénica que reflexiona sobre la función de la madre en la construcción de nuevas sociedades pacíficas y cooperantes. Ante la crisis del modelo capitalista y de la razón instrumental, estamos obligados a construir nuevos modelos de relación basados en el amor incondicional y en dinámicas fundamentadas en la cooperación y no en la destrucción. Creación (crianza) es actualmente una palabra radical y subversiva. La transgresión hoy en día está en nutrir, conservar, amar y criar ${ }^{6}$. (2009 s.n.)

Como veremos, este planteamiento no se aleja en demasía del que sustenta El conejito del tambor duracell, que se cierra precisamente con la propuesta de un cambio social que ponga los cuidados en el centro de la actividad política.

\section{EL CONEJITO DEL TAMBOR DE DURACELL}

Este artículo se fundamenta en El conejito del tambor de duracell, una traducción al español realizada por la autora de la versión catalana escrita en $2015^{7}$. El origen de la obra se remonta a un texto de 2006 de igual título ${ }^{8}$, en el cual predominaba una reflexión psicológica de corte existencial y el tema de la

5. <http://www.marta-galan.com/index.php?Mparam=creaciones-2016-1999\&Sparam= morir-damor-aqui-2011>, consultado el 26-05-2017. La traducción es propia (T.P.).

6. T.P.

7. El conillet del tambor de duracell constituye el primer texto de Galán escrito íntegramente en catalán. Tanto esta versión como la española datan de 2015 y pueden encontrarse en la web personal de la autora: <http://www.marta-galan.com/index.php?Mparam=creaciones2016-1999\&Sparam=conillet $>$, consultado el 26-05-2017. Para facilitar la comprensión, en nuestro artículo trabajaremos con la versión española, que difiere del original catalán en algunas modificaciones de estilo de corte menor. Solo anotaremos los cambios sustanciales a nivel de significado y, puesto que el documento no tiene numeración de página, referiremos las citas según su número de sección.

8. No disponible en versión impresa o digital. De esta primera versión surgió también, en 2007, el espectáculo Melodrama, que fue creado junto a Santiago Maravilla y cuyo texto 
maternidad quedaba en segundo plano. El texto de 2015 surge cuando el actor Marc Martínez se interesa por el original de 2006 y le propone a Galán montarlo con Clara Segura, una de las grandes actrices de la escena catalana. Ante la propuesta, la autora siente la necesidad de reescribir la pieza de acuerdo con una situación que la distanciaba sustancialmente de su propio discurso en 2006: había sido madre dos veces. De ello surge en 2015 El conillet del tambor de duracell, una versión más extensa y donde todos los pasajes añadidos contribuyen a politizar la experiencia de la maternidad: así, la figura del conejito de duracell que se queda sin pilas, inicialmente ligada a un cansancio psicológico y profesional (Nicolau/Galán), se convierte en símbolo del agotamiento de las madres en el actual contexto social.

La pieza es un monólogo dividido en 12 secciones de extensión irregular pronunciado por una protagonista sin nombre, lo cual desdibuja al mismo tiempo los límites entre su dimensión ficticia y autobiográfica y entre su propia voz y la de otras muchas madres. La protagonista es una mujer de mediana edad que mantiene una relación heterosexual (no se especifica si está casada o no), de clase media y cultivada, trabajadora y madre de un hijo de ocho años y una hija de cinco. Su monólogo se inicia en presente con un episodio que funciona como la gota que viene a colmar el vaso: la recepción de una carta de la escuela porque su hijo lee sin cesar «todo tipo de libros extraños» y desatiende sus obligaciones $(2)^{9}$. Seguidamente asistimos a la reunión de la protagonista con el tutor del hijo, la vuelta a casa después de las actividades extraescolares y el momento de poner los niños a dormir. El resto de la obra prosigue con el hilo de las reflexiones iniciado en la primera parte para entrar de pleno en consideraciones más amplias que interpelan al público. El monólogo mezcla descripciones realistas con visiones hiperbólicas e hipótesis delirantes que sirven para subrayar el mensaje; alterna tonos cómicos con sarcasmos, pasajes tiernos con tiradas reivindicativas, y momentos de desesperación y rabia con exposiciones mesuradas. Todos sus recursos estilísticos se ponen al servicio de una voz que quiere representar también a muchas otras: la del símil del conejito de duracell, cuya energía dura más que la de cualquier otro, pero a quien, aun así, están empezando a acabársele las pilas.

puede encontrarse aquí: <http://artesescenicas.uclm.es/index.php?sec=artis\&id=74>, consultado el 09-10-2017.

9. Quien explore la obra de Marta Galán se dará cuenta rápidamente de que muchos motivos y pasajes se repiten de una obra a la otra. Conillet no es una excepción y recupera pasajes de Protégeme, instrúyeme (la carta de la escuela), Madres, tetas y nanas (el árbol como compendio de belleza y lugar de disolución), Morir de amor aquí (la sed de ser amada y probar muchos cuerpos) o la alusión al portazo de Nora Helmer (Dark figurantes). 


\subsection{La (im)posibilidad de conciliar trabajo productivo y trabajo reproductivo}

En su entrevista con Óscar Cornago, Galán afirma: «nunca empiezo una nueva creación si no tengo clara una especie de «tesis». Es decir, inicio un nuevo trabajo de creación a partir de una intuición, pero inmediatamente me pongo a buscar materiales teóricos y críticos que puedan dar consistencia a esa intuición» (Cornago 175). En el caso de El conejito..., la fuente más directa (Nicolau/Galán) son los trabajos de María Jesús Izquierdo y de Silvia Federici. Los estudios de esta última demuestran que una de las bases fundamentales del capitalismo es el trabajo no remunerado de las mujeres, que típicamente se han hecho cargo de la reproducción y del bienestar físico y moral de los trabajadores en lo que «siempre ha aparecido como si se tratase de un acto de amor» (62). En la actualidad, las reivindicaciones de Federici no sólo han sido desoídas por las estructuras de poder, sino también por buena parte del movimiento feminista, más ocupado en abrirse camino en el mundo laboral masculino que en reivindicar un cambio de paradigma que proporcione un lugar central a las tareas reproductivas en nuestras sociedades (47). Siempre según Federici, «la ilusión de que el trabajo asalariado podía liberar a las mujeres no se ha producido» $(2014$, s.n.), puesto que la masiva incorporación de las mujeres al mercado laboral (en los países del primer mundo) ha acarreado para ellas la aparición de la llamada «doble jornada» (laboral y doméstica). Y ello es así, en gran medida, porque la incorporación de las mujeres al trabajo remunerado no ha ido acompañada de «la equivalente alza en la proporción de hombres participando en el trabajo no remunerado» (Goñi-Legaz, Ollo-López y Bayo-Moriones 526). En el estado español, solo el 12\% de mujeres afirman compartir con sus compañeros de forma plenamente equitativa las tareas del hogar, mientras que la media europea se sitúa en el $25 \%(526)^{10}$.

En el imaginario social y el discurso político, la doble jornada se ha normalizado y reforzado bajo el término de «conciliación» como la opción de vida más deseable para las mujeres. Tanto Silvia Federici como Elizabeth Badinter argumentan que el mismo concepto es una trampa, puesto que prioriza la tarea

10. T.P. Como explican Goñi-Legaz, Ollo-López y Bayo-Moriones, la tasa de ocupación para las mujeres españolas de entre 16 y 64 años aumenta de un $22.9 \%$ en 1964 a un 53\% en 2009 (516). Sin embargo, su estudio demuestra que incluso en 2010 el reparto del trabajo reproductivo en parejas heterosexuales con dos sueldos continúa siendo profundamente desigual: el $55.22 \%$ de mujeres encuestadas afirman realizar todas las tareas del hogar, frente a un $1.48 \%$ de hombres; el $44.16 \%$ de mujeres declaran compartir las tareas frente al $64.87 \%$ de hombres; y un 33.29\% de hombres declara no realizar ninguna tarea en el hogar, frente al ínfimo $0.61 \%$ de mujeres (521). 
de crianza y la educación de los niños ante las posibles reivindicaciones relativas al bienestar de las madres (Badinter 135), y relega al terreno privado de la organización personal una cuestión profundamente pública (Federici 2013). Además, no debemos olvidar que a estas exigencias tácitas se suman otras, como la exigencia de belleza y de disponibilidad sexual, lo que en conjunto sustenta el mito de la «superwoman».

La protagonista de El conejito... es, en palabras de la autora, «una persona al límite pero que es muy capaz de comunicarnos con claridad y contundencia lo que piensa» (Soler Bort). Así, se declara con sumo sarcasmo orgullosa de haber podido conciliar vida laboral y familiar, añadiendo que ésta debe ser la misión de una mujer, sin esperar que nadie valore su trabajo reproductivo puesto que lo realmente valioso, en nuestra sociedad, es producir:

CONCILIAR./ Hacer compatibles las horas de crianza/ (esas horas muertas, improductivas, irrelevantes)/ con las horas verdaderamente productivas;/ las que cuentan,/ computan,/ las que le van a pagar,/ [...] ¡Estas sí que son horas productivas!/ Pero dar la vida, conservar la vida, iqué idiotez!/ Te jodes y CONCILIAS. (3)

Como mujer, además, debe ceñirse estrictamente a esta doble tarea, bajo riesgo de ser tildada de invasiva si opta por no tener un empleo o de madre demasiado desprendida si dedica poco tiempo a la crianza: «iMe ves a mi cara de conformarme con ser ama de casa/ o atreverme a ser vicepresidenta del gobierno?/ ¡NO!/ YO CONCILIO./ Lo hago todo./ ¡Soy una jodida máquina y puedo con todo./ (No sabéis de qué manera puedo con todo)! (3)». El texto erige la situación de la protagonista en ejemplo de la de muchas otras mujeres, aclarando además que, si son ellas las que se ven obligadas a desdoblarse, es porque ellos no lo están haciendo: «YO CONCILIO/ TÚ CONCILIAS/ ELLA CONCILIA/ NOSOTRAS CONCILIAMOS/ VOSOTRAS CONCILIAIS./ ELLOS NO CONCILIAN» $(3)^{11}$.

En uno de los pasajes más memorables de la pieza, la protagonista explica a qué destina los 1440 minutos de un día tipo ${ }^{12}$. Al final del recuento, revela que solo le quedan 14 minutos de «vida»: «de eso que yo llamo «vida»: el cerebro disponible, las manos desocupadas» (6). El resto los destina a trabajar, limpiar, cocinar, transportar a sus hijos, sacar a la perra y asearse (treinta minutos «nivel usuario: básico» (6)). En su explicación, aclara que los minutos

11. En la versión catalana esta alusión aparece aunque de modo menos explícito: «JO CONCILIO/ TU CONCILIES/ ELLA CONCILIA/ NOSALTRES CONCILIEM/ VOSALTRES CONCILIEU/ ELLES CONCILIEN».

12. El pasaje del cómputo de minutos fue escrito durante el proceso de creación junto a Clara Segura y Marc Martínez, y su autoría es compartida con ellos. 
destinados al trabajo «son los únicos minutos del día/que obtienen remuneración» (6), y siguiendo las tesis de Federici no duda en llamar los 98 minutos de tareas de la casa «TRABAJO DOMÉSTICO»: una "presencia desapercibida», de «cuerpo en acción brutal» (6). En otras palabras, la protagonista trabaja prácticamente todas las horas del día sin contar el sueño, habiéndose visto obligada a renunciar a todo lo que atañe a la vida personal, como «Las cenas con amigos $[\ldots] /$ Los proyectos preciosos $[\ldots] /$ El consumo cultural $[\ldots] / \mathrm{La}$ lectura $[\ldots]$ / Los ratos perdidos mirando el mar $[\ldots] »$, a los que considera, irónicamente, «prescindibles» (3). Por lo tanto, la maternidad la ha llevado a una situación límite en la que el primer tributo que ha tenido que pagar ha sido el de su identidad como mujer independiente y autorrealizada. Como apunta Hays, en una sociedad que exige a las mujeres con hijos que sean a la vez competentes profesionales y madres abnegadas y amorosas, «las complejas estrategias que las madres usan para afrontar estas lógicas contradictorias iluminan el tributo emocional, cognitivo y físico que deben pagar las madres de hoy» (Hays 220 citado por Fernández Pujana 32). No queremos dejar de mencionar que la protagonista subraya su elección de no ceder su «tiempo de crianza/ a una mujer del Ecuador o polaca, rusa, filipina, española, catalana» (3). Con esta alusión se apunta a lo que Federici considera un síntoma de la grave crisis de cuidados que sufre actualmente el mundo occidental: el traspaso de las tareas de cuidado a mujeres más pobres y mayoritariamente inmigrantes, lo cual «solo crea nuevas desigualdades entre las mujeres y alarga la crisis reproductiva» $(2013,180)$.

Al final del pasaje la protagonista arremete contra la película La sal de la tierra de Wim Wenders, un buen ejemplo de narrativa épica contemporánea en la que los arduos viajes del «héroe», el célebre fotógrafo Sebastião Salgado, oscurecen por completo una misión considerada muy menor: la de su mujer Leila, condenada a criar sola a sus dos hijos -uno de ellos con síndrome de Down- y a conciliar vida laboral y tareas reproductivas sin ninguna ayuda. La acusación pone de relieve hasta qué punto la invisibilización de las vidas de las mujeres y de las tareas reproductivas es una herencia aún vigente en la producción cultural de occidente, y evidencia por qué trabajos como la misma obra que la contiene son a la vez necesarios e innovadores.

\subsection{Sentimientos maternos: amor y entrega, pero también culpa y miedo}

Si bien, como argumenta Federici, el patriarcado capitalista ha devaluado siempre la importancia de las tareas reproductivas, no por ello ha dejado de promover un mandato exacerbado de maternidad, sin el cual no podría reproducir su fuerza de trabajo. Según autoras como Sharon Hays (1996) o Elizabeth 
Badinter (2011), la incorporación de las mujeres al trabajo asalariado ha traído consigo un aumento de dicho mandato y de las responsabilidades que lo acompañan. Desde una posición igualitarista, Badinter sostiene que, entre 1980 y 2010, se ha devuelto «la maternidad al centro del destino femenino» (11) gracias a una ofensiva naturalista que con el argumento de «lo natural» insta a las madres a invertir más tiempo en la lactancia y la crianza, bajo la premisa de la centralidad del bebé, ante el cual «la preocupación por una misma debe ceder el puesto al olvido de una misma» (23).

Otras autoras sostienen desde el feminismo de la diferencia que la vuelta a la crianza natural conllevaría, al contrario, la recuperación de una maternidad propia, soterrada bajo el modelo de madre impuesto por el patriarcado. En este sentido, Casilda Rodrigáñez defiende los diferentes estadios de la maternidad biológica como un «estado sexual [que] ha sido robado a la vida sexual de la mujer», en una "dimensión clave del matricidio y de la eliminación de la madre» (25). Según esta tesis, recuperar la naturalidad de los procesos de embarazo, parto y lactancia no iría en contra de la madre, sino que le permitiría acceder a un ámbito de su propia sexualidad que le ha sido vedado bajo las formas represoras del instinto materno -concepto animalizante y patriarcal opuesto al propiamente humano «deseo materno»-. La protagonista de $\mathrm{El}$ conejito... sería más afín a estas posiciones, al igual que su autora, que cita como referente Maternidades subversivas de María Llopis (Galán 2017), una recopilación de entrevistas que, entre otros aspectos, ahonda en las tesis de Rodrigáñez para presentar vivencias de la maternidad que se alejan del «contexto capitalista y patriarcal en el que se desarrolla asexuada, medicalizada, biologizada y desempoderada» (contracubierta).

Las dos corrientes del feminismo coinciden, en cualquier caso, en los resultados nefastos que acarrea una maternidad intensiva desarrollada en el contexto productivo occidental contemporáneo. Badinter los resume en una triple contradicción que aparece plenamente reflejada en la obra de Galán. En primer lugar, social: el ya mencionado choque entre el exacerbado mandato de reproducción y la devaluación de las tareas reproductivas en el imaginario social, que los citados pasajes sobre la conciliación denuncian sin ambages. En segundo lugar, conyugal, ya que «la idea estereotipada de que el hijo refuerza la solidez de la pareja ha fracasado» (180), y la relación de pareja de la protagonista es un ejemplo de ello. Y, finalmente, identitaria, puesto que muchas madres «se sienten divididas entre su amor por el hijo y sus deseos personales» (144), como es el caso de la protagonista, que ha debido renunciar a todos sus deseos personales por amor a los hijos. 
El fundamento del texto que nos ocupa es la tensión entre los sentimientos reales de amor y entrega que unen a la protagonista con sus hijos y el tipo de maternidad a la cual la realidad social la ha conducido. El texto se abre y se cierra con un mismo pasaje, reproducido también en la sección cinco, que funciona como contrapunto al resto de la pieza y simboliza metonímicamente los sentimientos positivos que puede generar una maternidad deseada y gozada: «Estoy aquí./ Sentada./ Paciencia infinita./ Toda tetas./ Toda oídos./ Expuesta./ AMÁNDOTE-AMAMANTÁNDOTE/ Aquí, para ti, como una ofrenda./ Este es mi pequeño secreto:/ existir para ti como una ofrenda» ( 1 y 12). La última línea del pasaje ofrece la clave para entender cómo el deseo de darse a los hijos que siente la protagonista queda pervertido por el modelo de maternidad imperante, que le exige una versión exacerbada de una entrega difícil de sostener a largo plazo. Esta lectura se ve reforzada por un pasaje de la apoteosis final, en el cual la protagonista contrapone las experiencias del parto y de la lactancia, vividas en su caso como una experiencia satisfactoria, algo «sexual, físico, placentero» y que «sólo suma» (10); a los años posteriores de crianza:

Pero criar con presencia, con gratitud, con alegría, serena y firme,

día tras día, año tras año, hasta que pasan tres, cuatro, cinco, trece, dieciséis años,

sin tribu,

sin leyes que nos protejan a las madres,

a los hijos, a las hijas;

a las personas que cuidan, cargan, acarician, cambian pañales, dan de comer, miran a los ojos, dan la mano, escuchan y ponen a dormir, es una EXTORSIÓN y sólo resta. (10)

Esta «EXTORSIÓN» es también la que viven muchas mujeres reales, primeras perjudicadas de las desastrosas consecuencias de las políticas de conciliación y de igualdad en España. En la actualidad, en el Estado español son muy deficientes las bajas de maternidad y paternidad, la cobertura de «centros públicos de educación infantil para niños de cero a tres años», la poca flexibilidad y larga duración de las jornadas laborales y, en un sentido más amplio, el gasto público sobre las familias, insuficiente «para estimular la igualdad de género en los hogares españoles» (Gracia y Bellani 42-43). Y todo ello porque, una década después de su creación, la Ley Orgánica 3/2007 para la igualdad efectiva de mujeres y hombres, pionera en su momento, continúa sin enmiendas y está muy lejos de aplicarse. Dicha situación aboca a muchas madres a criar en una sociedad que da completamente la espalda a los cuidados, lo cual repercute negativamente tanto en sus maternidades como en sus empleos (Gracia y Bellani). Además, la imagen imperante de una maternidad intensiva en la que no tienen cabida los sentimientos negativos inherentes a cualquier relación 
humana y mucho menos las problemáticas propias de la conciliación, convierte a las madres en presas fáciles de la culpa, la desorientación y el miedo. Por ejemplo, varios estudios (Badinter, Imaz) demuestran que las madres trabajadoras se ven a sí mismas como alejadas de un modelo de crianza intensiva que consideran el ideal, incluso reconociendo que éste resultaría «frustrante para su propio desarrollo personal» (Imaz citada por Fernández Pujana, 40). Por otro lado, y como los citados trabajos argumentan, el exacerbado sentimiento de responsabilidad actual para con los hijos es histórico y está ligado a la contemporaneidad occidental, en la que se produce un «incremento de obligaciones con respecto al hijo que se ha escogido dar a luz» (Badinter 11) y del que, por lo tanto, se es especialmente responsable ${ }^{13}$.

En el caso de la protagonista, la actitud que mantiene hacia los hijos pone de relieve lo opresor del modelo de maternidad imperante y los sentimientos negativos que genera. Por un lado, dos o tres actuaciones irreverentes y de claro carácter provocador -como fumarse un cigarrillo a medias con su hijo, discutir con él gritando y agarrándole el brazo o mandar a los dos retoños a la cama sin cenar (la noche en la que asistí a la función se oyeron bufidos de desaprobación en esta escena $)^{14}$ - ponen de relieve hasta qué punto en los últimos años se han vuelto impensables ciertas libertades por parte de las madres, cada vez más obligadas a renunciar a cualquier actividad que pueda perjudicar a sus hijos (Badinter 85). Por el otro, el peculiar «entrenamiento» al que la protagonista somete a sus hijos -buen ejemplo del gusto de la autora por lo excesivo- deja entrever que sus sentimientos maternales son el amor y la entrega, pero también el hartazgo, la culpa y el miedo.

El «entrenamiento» en cuestión es un delirante programa de lecturas de disciplinas diversas y múltiples actividades extraescolares que deben preparar a sus hijos por igual, tanto al niño como a la niña. Dicho programa define a la protagonista, por un lado, como sujeto activo que ejerce un control sobre su prole y la educación a la que la somete, lo cual la aleja de la figura de víctima sin recursos. Por el otro, el entrenamiento constituye una versión hiperbólica del alto grado de exigencia que reviste actualmente la educación de los hijos, y que unida a la ideología de la maternidad intensiva multiplica los deberes de la madre:

13. Una alusión a esta cuestión aparece en la sección 10: «PARTENOGÉNESIS./ Dar la vida por decisión propia, a todo riesgo./ Bajo su única responsabilidad./ PARTIRSE./ Hacerse dos».

14. Representación del 31 de marzo de 2017 en el Ateneo de Cerdanyola del Vallès, en el marco de la gira por Catalunya. 
[los cuidados maternos] ya no se reducen únicamente a los cuidados corporales y afectivos, implican también una atención escrupulosa al desarrollo psicológico, social e intelectual del hijo. La maternidad representa, más que en el pasado, un trabajo a tiempo completo. (Stanworth 1987, 143, citado por Badinter 14)

El erigirse como única responsable de la educación de sus hijos comporta, en efecto, hacerse cargo de todas sus consecuencias, lo cual genera indefectiblemente una carga añadida de culpabilidad y miedo: «Al principio: miedo/ $\mathrm{Al}$ final: miedo igual, pero soportable./ Miedo de cagarla en todos los sentidos./ Que todo te salga mal./ El tiro por la culata./ Criar cuervos» (6). Para esta mujer que dice no poder «imaginar para [su]s hijos ni un segundo de infelicidad» (4), la crianza puede revelarse muy culpabilizadora, a pesar de su programa para que sus hijos devengan autosuficientes.

Esta contradicción arroja luz sobre la perversión que supone minimizar las ayudas a aquellas personas que se ocupan de la crianza al mismo tiempo que se les exigen resultados imposibles. En palabras de Sau, «el orden social moderno pone la infancia en sus manos [las de la madre] a full time y luego le reprocha que sea complaciente, posesiva o demasiado tolerante», criticándola indistintamente por ser demasiado intensiva o por ser «poco cálida, distante, ausente [...] capaz de ser feliz al margen de su maternidad» (35). Por eso la protagonista cada día les dice a sus hijos que les quiere «más que a nada en el mundo» (3), para que no olviden sus sentimientos reales a pesar de que cada vez se sienta con menos fuerzas para continuar:

¿Os he dicho que sois lo más importante que me ha pasado en la vida?

¡La cosa más bella, más perfecta y más alucinante que he hecho en la vida!

Pero a veces las madres necesitan descansar.

Salir a dar un paseo.

Tomar un poco el aire.

$\mathrm{Y}$ a veces las madres se ausentan.

O se mueren, las madres.

A veces también pasa eso: que las madres se mueren.

Y por eso tenéis que ser fuertes como titanes, como leones.

¡Fuertes, imperturbables y felices!

¡ATARAXIA, ATARAXIA! (10)

El pasaje resume la ansiedad que supone para la protagonista darse cuenta de que, a pesar del amor que profesa a sus criaturas, la situación la sobrepasa: finalmente, resulta desolador constatar que aquello que la protagonista desea para sus hijos, la felicidad y la ataraxia -la «imperturbabilidad del ánimo ante la adversidad» (2)-, está lejos de poder ser una realidad para ella, tanto en lo que atañe a su vivencia de la maternidad, como en lo referente a su tiempo personal 
y a su vida afectiva y sexual. Respecto a esta última, la protagonista despliega a lo largo de tres secciones una visión muy desencantada: según explica, en los 14 minutos de «vida» que tiene al día, intenta recuperar algo de la intensidad sexual que la unió a su pareja al inicio, aunque su relación se basa ahora en dinámicas de poder y abuso ${ }^{15}$. Al fin y al cabo, sus deseos profundos-vivir su sexualidad y su afectividad más allá de la monogamia, y reproducirse siguiendo únicamente su deseo de ser madre- quedan muy alejados de su realidad -«Soy una mujer monógama y tengo sólo 2 hijos» $(7)^{16}$. Del mismo modo que el hilo conductor de la pieza se encarga de desmitificar la maternidad, estos pasajes ponen en duda el discurso del amor romántico-«Alguien me debería haber explicado/ [...] que no iba a existir ningún hombre capaz de hacerme feliz./ [...] ¿Por qué alguien no les explica a los niños y a las niñas que el amor romántico es letal?» (7) - y el modelo tradicional de familia junto con el «amor monógamo» (7), problemático tanto para la vivencia de la maternidad como en relación a la pareja: «Crear familias a partir de parejas que follan/ (parejas que durante un tiempo follan y después se cansan, es natural: ¡una mala idea!)/ Tener hijos y criarlos junto al padre biológico: ¡Una mala idea!» (7).

\subsection{Reivindicación de la importancia política y social de los cuidados}

El clímax de la obra se produce en la sección 11 -seguida solo del leitmotiv de la lactancia-, cuando «el conejito del tambor de duracell» anuncia que se le están acabando las pilas, y da a elegir entre una revolución completa en el tratamiento que la sociedad da a los cuidados y el retiro de todas sus ocupaciones, por el que finalmente opta: «Sí, quiero que me dejéis descansar» (11).

En un pasaje previo de la obra, la protagonista presenta su visión sobre el trabajo como algo totalmente utilitario - «Voy, lo hago y cobro el dinero./ Voy, lo hago y me pagan.» (4)-, un punto de vista anticapitalista que va en contra del discurso neoliberal dominante sobre el emprendimiento y la autorrealización a través de la actividad remunerada. El pasaje concluye con la exposición de un deseo -atribuido explícitamente a El intercambio simbólico y la muerte de Baudrillard-: que todos los trabajadores desaparecieran, murieran simbólicamente, como forma de sustraer su producción y su propio cuerpo productor

15. A nuestro parecer, el defecto principal de la pieza -aun teniendo en cuenta que las creaciones de Galán no son tramas cerradas ni con vocación psicológica- sería no problematizar la nula implicación de la pareja en las tareas domésticas.

16. El pasaje que concluye con esta afirmación no aparece en la versión catalana. Se trata de 18 versículos que reproducen parte de un fragmento de Madres, tetas y nanas donde la protagonista declara querer pasar el resto de su vida pariendo y criando, ya que su «cerebro sólo ha encontrado paz en ese estado químico, anímico» (7). 
al capital. La explicación anticipa la resolución final de la protagonista, que una vez más se relaciona también con las ideas de Federici: «Si no hay reproducción, no hay producción. Si ese trabajo que hacen las mujeres en las casas es el principio de todo lo demás: si las mujeres paran, todo para; si el trabajo doméstico para, todo lo demás para» (2014, s.n.). Por eso el deseo de dejarlo todo y el cansancio de la protagonista funcionan metonímicamente como los de todas las mujeres: «¿Sabes por qué tengo que pedirte, por favor, que me protejas de mis deseos?/ Porque son letales./ Porque suponen el fin del amor romántico y de toda esa mierda./ El fin de la reproducción sexuada, del matrimonio, la monogamia... ¡ todo ese tinglado!» $(11)^{17}$.

Los exabruptos de hartazgo y rabia que encontramos a lo largo de la obra culminan en esta sección con una improbable hipótesis: que, de repente, la protagonista deje de interesarse por los que la rodean y se dedique solo a su placer, transgrediendo así el tradicional rol femenino de anteponer siempre el cuidado de los otros a las propias necesidades, y de actuar con discreción para no destacar más que sus homólogos masculinos. Después de lanzar su hipótesis, sin embargo, reconoce que se trata en realidad de una visión exacerbada del miedo y la culpabilidad que siente al imaginar que podría no haber dedicado suficiente tiempo a sus seres queridos: «Tengo miedo de que llegue un momento en el que ya no me interese el mundo./ Ni la gente./ [...] Tengo miedo de no haberles escuchado lo suficiente,/ [...] Tengo miedo de haber vivido sólo y exclusivamente para llamar la atención» (11). La hipótesis sirve para poner en evidencia hasta qué punto la figura de la madre requiere del sacrificio concreto de la mujer -ella sabe que, si se entrega al placer, la llamarán «ególatra, egoísta, putón, mala madre (11)»- y sitúa la obligatoriedad de este sacrificio en el contexto más amplio de una actitud femenina prototípica, evidenciando cómo el género juega en contra de las mujeres.

No obstante, y a pesar de todos sus miedos, la protagonista acaba por declarar su extenuación y amenaza con cesar su actividad si no le traen los medios suficientes para continuar ejerciendo su maternidad dignamente:

Dadme una nueva sociedad donde dar la vida, conservar la vida, estar al cuidado de la vida (de la de los bebés, los niños, los jóvenes, los viejos) con amor, con presencia, día a día, sea alguna cosa que fundamente las estructuras sociales, que condicione los planes económicos, las derivas políticas, las acciones reales. (11)

17. La versión catalana añade: «Perquè suposen la fi del món./ La fi del vostre món». 
A medida que desgrana la lista de médicos, juristas, leyes, medios de producción y otros elementos necesarios para que ello sea posible, una ira creciente impregna sus reivindicaciones, poniendo de manifiesto hasta qué punto la crianza es una actividad invisible que nadie agradece:

¡Dadme las gracias, hijos de puta!

¡Protegedme y dadme las gracias!

¡Ponédmelo más fácil, dadme apoyo!

Estructuras legales en las que ampararme.

¡Más guarderías, Catovit gratis!

¡Hacedme estatuas, bustos, colocadlos en las plazas!

¡Ponedle mi nombre a una calle o a un parque!

¡Yo sola no puedo! (11)

Finalmente se compara con el conejo de duracell, cuya batería es de larga duración y alto rendimiento, pero que incluso así se está quedando sin energía, y pide refuerzos porque: «es muy peligroso que yo me detenga...» (11). Después añade: «Y si no tenéis todo esto que os he pedido,/ TODO, dejadme descansar, por favor». La conclusión, que apunta reminiscencias del famoso portazo de Nora en Casa de muñecas de Ibsen, se cierra con una alusión a unos versos de Alejandra Pizarnik: «Quiero un silencio perfecto, por eso hablo» (11). Esta paradoja resume la lucha de la protagonista: necesita descanso después de un cometido agotador; pero para llegar a él es necesario que hable primero sobre su situación y la de muchas mujeres que son madres en la actualidad, para empezar a sacarla de la invisibilidad social a la que está desterrada.

\section{LA PUESTA EN ESCENA DE MARC MARTÍNEZ Y CLARA SEGURA}

La versión adaptada por Marc Martínez bajo el título Conillet se estrenó en el Festival Temporada Alta de Gerona el 6 de noviembre de 2015. Estuvo un mes en la cartelera del Teatre Lliure de Barcelona (11/11/2015-13/12/2015, con prórroga incluida) y posteriormente se exhibió en el Festival Grec de Barcelona (19-07-2016-05/08/2016) y en una gira por Cataluña (01/04/201607/05/2017). En la dirección, el actor Marc Martínez demuestra su competencia en un terreno que no le es propio y Clara Segura, con su habitual brillantez y amplitud de registros, despliega una energía admirable para representar a la protagonista de la obra, lo cual le mereció el Premio de la Crítica 2015 a la Mejor Actriz Principal y el Premio Butaca 2016 a la Mejor Actriz Teatral. La versión producida por el Lliure y Bitò Produccions está pensada para agradar a un público exigente pero relativamente amplio, y tiene una impronta más refinada y sobria de lo que es habitual en Galán. Como ella misma afirma, escribir para el Lliure supone «un cambio de contexto [...] de estatus» (Gázquez 475) 
y, casi sobra decirlo, de presupuesto. La escenografía, de Alejandro Andújar, se reduce a una gran boca de desagüe que apunta a múltiples simbologías - «ya puede simbolizar un agujero negro, un refugio o una vulva inmensa», interpreta Foguet- con el cual la actriz interactúa a lo largo de la pieza.

La versión de Martínez -primera dirección ajena de un texto de Galántiende a reducir el texto original, lo cual demuestra ser un acierto ante la puesta en escena, con una duración y un ritmo impecables. Sin embargo, la adaptación no solo reduce su duración, sino también su componente subversivo, limando el lenguaje de connotaciones políticas -conciliación, trabajo doméstico, trabajo no remunerado, amor romántico, monogamia...-y menguando el alcance de la reflexión sobre la dimensión política de la maternidad. Así, desaparecen los citados pasajes sobre la conciliación (3) y la reivindicación de los cuidados como centrales para la construcción de una sociedad más justa (11), y con ellos la insistencia en la dimensión política del trabajo de las mujeres y las propuestas políticas que contiene la pieza. Desaparece también la crítica a $L a$ Sal de la tierra y por tanto la metacrítica hacia los productos culturales contemporáneos que reproducen el discurso patriarcal. Asimismo, es eliminado el pasaje sobre la «mala idea» (7) de mezclar sexo, familia y amor, limitando así la deconstrucción de la familia heteropatriarcal, junto con los deseos femeninos que la ponen en duda - ¿hasta qué punto sigue siendo subversiva la expresión de determinados deseos en boca de una mujer ${ }^{18}$ En consecuencia, la protagonista de Martínez tiene un discurso muy similar a la de Galán, pero menos apoyos teóricos y políticos para justificarlo -habiendo quedado difuminado el argumentario de Federici-, y, por lo tanto, menos autoridad, reduciendo su potencial de cuestionamiento y menguando la capacidad para trasladar determinadas ideas al público.

A grandes rasgos, la puesta en escena de Martínez convierte un discurso que tenía mucho de deconstrucción de la figura de la madre, en su reivindicación. Según la autora, el director acerca su personaje a una visión de la madre «más idealizada, este perfil femenino más todopoderoso», en lo que probablemente fuera «un homenaje a su madre» (Galán 2017). El lenguaje no verbal elegido por Martínez va acorde con este carácter de «homenaje» que la autora señala: así, antes del inicio de la función se ve a Segura bailando y

18. Junto con los casos citados, consideramos especialmente significativa la supresión total o parcial de la pelea con el hijo; la alusión a la delegación de la crianza en otra mujer; la referencia a Baudrillard; la designación de los minutos de trabajo del día como los únicos «que obtienen remuneración» (6); la alusión a las tareas domésticas como «cuerpo en acción brutal» pero no como «TRABAJO DOMÉSTICO» ni como «presencia desapercibida» (6); y, finalmente, el pasaje sobre su deseo polígamo y su sed de ser querida. 
haciendo estiramientos largo rato al son de una música electrónica, preludio del fuerte ejercicio físico que realizará durante la función y trasunto material del carácter «todopoderoso» de este animal doméstico que es el «conejito». $\mathrm{Su}$ indumentaria sobria pero atractiva -camisa y americana con deportivas negras, y posteriormente vestido negro- podría ser la de cualquier mujer de clase media hoy y por lo tanto la sitúa más cerca de un perfil medio que de uno más disruptivo respecto al modelo de mujer dominante. Asimismo, Martínez añade una coda en la que Segura saca al escenario una olla de lentejas con chorizo y después de cenar ella misma para «ganar tiempo», invita al público a servirse. Esta conclusión reproduce el final de Madres, tetas y nanas, y va muy acorde con la tónica de Galán, que a menudo termina sus espectáculos en momentos festivos, con bailes, bebida o comida. No obstante, y a pesar de acercar la representación a los códigos habituales de la autora, el cierre no deja de suavizar el contenido reivindicativo del clímax, sustituyéndolo por un tono final más festivo y conciliador.

Algo parecido ocurre con el uso recurrente del humor: si bien en buena parte sarcástico -y subrayado por la magnífica risa sardónica de Segura-, este recurso no deja de aliviar la tensión de la pieza. Por todo ello, adaptación textual y puesta en escena concurren en otra reducción sin duda muy significativa: la del grado de incomodidad que pueda experimentar el sujeto masculino del público.

\section{CONCLUSIONES}

La actual incorporación de las mujeres al mundo del teatro en tanto que directoras y autoras, aunque incipiente, está ya cambiando la idiosincracia del género dramático y poniendo sobre la mesa temas hasta ahora silenciados. Así, las iniciativas escénicas que a día de hoy problematizan la maternidad y la paternidad parten en su mayoría -lamentablemente- de autoras femeninas. La pieza de Marta Galán, junto con su proceso de creación, es un buen ejemplo de ello y de cómo las dinámicas del mundo teatral afectan y distribuyen la presentación de ésta y otras temáticas ligadas a la mujer.

En El conejito del tambor de duracell, Marta Galán propone una reflexión, ligada a su experiencia concreta de mujer heterosexual que ha sido madre (Galán 2017), que cuestiona el modelo de crianza y de familia actual y arroja luz sobre el desamparo emocional, laboral y económico que puede generar la maternidad en nuestra sociedad. Se trata, por lo tanto, de una obra que se inserta en la línea de piezas que destilan materiales autobiográficos que sirven para cuestionar «el concepto de identidad» (Gázquez 56), desde una posición claramente política. En este sentido, la fuerte carga teórica de la pieza cobra 
una vitalidad nueva, al verse materializada en las experiencias reales de una mujer concreta.

El discurso de la protagonista parte de una perspectiva interseccional que aúna anticapitalismo y feminismo de la diferencia. En cuanto a su maternidad, no es de tipo intensivo -puesto que tiene una ocupación remunerada que le ocupa entre ocho y diez horas cada día-, pero sí bastante presente -como la de muchas mujeres que concilian-, al haber elegido no delegar cuidados en otra mujer y al haber renunciado a autorrealizarse a través de actividades personales. La cuestión, casi sobra decirlo, es identificar hasta qué punto se trata de una elección verdadera o bien de una situación forzada por un entorno social que delega enteramente los cuidados en las mujeres. Ella no deja de manifestar esta ambigüedad para defender la posibilidad para «las personas que cuidan» (10) de disponer de tiempo, especialmente para el cuidado de bebés y niños, insistiendo en que la crianza y otras tareas reproductivas constituyen un trabajo no remunerado.

En su puesta en escena, como hemos visto, este conjunto de reflexiones se ve mermado en sus postulados más rompedores. No es baladí que ello coincida con el acceso a la escenificación para un público más amplio que el hasta entonces convocado por Galán: al tiempo que lima las connotaciones políticas de la pieza, la versión de Martínez transforma un texto cercano a lo postdramático en un monólogo tragicómico mucho más tradicional, en el que los cambios bruscos del texto quedan hábilmente solventados. En otras palabras, la producción del Lliure es más conservadora que los trabajos habituales de Galán tanto en su subversión del género como en términos de lenguaje teatral. Por ello el proceso de creación de Conillet, junto con el hecho de que sea esta institución faro del teatro barcelonés quien coproduzca la pieza, no hace sino reafirmar una tendencia general: cuanto más se sube en la jerarquía teatral, menos representación tienen las mujeres y, de manera paralela, más cercanas a un discurso patriarcal son las narrativas que las representan.

A pesar de todo, poner la maternidad en el centro de un objeto cultural, como hace Galán, implica sacarla de su devaluación sistemática para tratarla como «ámbito de oportunidad para conocer y analizar toda su complejidad en lo referente a las relaciones, [...] a las emociones, a las tensiones y contradicciones que genera», pero también como «locus privilegiado para analizar cuestiones como las relaciones de poder» (Fernández Pujana 25). Es decir, darle el estatus que se le ha negado sistemáticamente en la representación cultural occidental: el de una experiencia humana y por lo tanto compleja, diversa y crucial para sus protagonistas. Abordarla en tanto que espacio político 
significa, además, reivindicar su verdadero valor de trabajo, algo estrechamente ligado a la posibilidad de su revalorización simbólica, puesto que

Mientras que el trabajo reproductivo siga devaluado, mientras siga considerándose una tarea privada y responsabilidad exclusiva de las mujeres, estas siempre tendrán menos poder que los hombres para oponerse al Estado, y permanecerán en condiciones de extrema vulnerabilidad social y económica. (Federici 2013,179)

El conejito del tambor de duracell nos interpela, a través de su discurso potente, complejo, anárquico y subversivo, con un mensaje de importancia capital: sin igualdad de oportunidades en el terreno social y sin políticas centradas en la vida cotidiana de las mujeres, no habrá nunca igualdad en el campo simbólico y cultural, que es el que continúa sustentando, como nos recuerda Ana de Miguel, el patriarcado del consentimiento.

\section{REFERENCIAS BIBLIOGRÁFICAS}

Badinter, Elizabeth. La mujer y la madre: un libro polémico sobre la maternidad como nueva forma de esclavitud. Madrid: La Esfera de los libros, 2011.

Cornago, Oscar. Éticas del cuerpo: Juan Domínguez, Marta Galán, Fernando Renjifo. Madrid: Fundamentos, 2008.

Esteban, Mari Luz. «La maternidad como cultura. Algunas cuestiones sobre la lactancia materna y cuidado infantil». Medicina y cultura. Estudios entre la antropología y la medicina. Eds. Enrique Perdiguero y Josep M. Comelles. Barcelona: Edicions Bellaterra, 2000. 207-226.

Federici, Silvia. Revolución en punto cero. Trabajo doméstico, reproducción y luchas feministas. Madrid: Traficantes de Sueños, 2013.

Fernández Pujana, Irati. Feminismo y maternidad: ¿una relación incómoda? Conciencia y estrategias emocionales de mujeres feministas en sus experiencias de maternidad. Vitoria-Gasteiz: Emakunde/Instituto Vasco de la Mujer, 2014.

Foguet, Francesc. «Dones extenuades». El Temps 1642 (1 diciembre 2015): 94.

Galán, Marta. La Corporació/2009: superproduccions postdramàtiques d'un sol ús / un projecte de Marta Galán per a la Nau Ivanow / BCN. Barcelona: Departament de Cultura i Mitjans de Comunicació, Nau Ivanow, Escándalo Films, 2009.

Gázquez Pérez, Ricard. La escenificación del yo en los solos de las nuevas creadoras interdisciplinares en España: 2000-2014. Tesis doctoral de la Universitat Autònoma de Barcelona, 2014. <http://www.tdx.cat/handle/10803/384527>, consultado el 23-05-2017.

Goñi-Legaz, Salomé, Andrea Ollo-López y Alberto Bayo-Moriones. «The Division of Husehold Labor in Spanish Dual Earner Couples: Testing Three Theories», Sex Roles 63 (2010): 515-529. 
Gracia, Pablo y Daniela Bellani. Las políticas de conciliación en España y sus efectos: un análisis de las desigualdades de género en el trabajo del hogar y el empleo. Estudios de progreso 51. Madrid: Fundación Alternativas, 2010.

Hays, Sharon. The Cultural Contradictions of Motherhood. Yale: Yale University Press, 1996.

Imaz, Elixabete. Mujeres gestantes, madres en gestación. Representaciones, modelos y experiencias en el tránsito a la maternidad de las mujeres vascas contemporáneas. Leioa: Universidad del País Vasco, 2010.

Llopis, María. Maternidades subversivas. Tafalla: Txalaparta, 2015.

Miguel de, Ana. «Sobre el patriarcado del consentimiento». <http://www. tribunafeminista.org/2017/05/ana-de-miguel-sobre-el-patriarcado-del-consentimiento/>, consultado el 28-05-2017.

Nicolau, Adriana. «Entrevista a Marta Galán». 25 mayo 2017 (material inédito hasta publicación de tesis doctoral).

Requena Aguilar, Ana. «Entrevista a Silvia Federici. Es un engaño que el trabajo asalariado sea la clave para liberar a las mujeres». El diario, 24 mayo 2014. <http://www.eldiario.es/economia/engano-trabajo-asalariado-liberar-mujeres_0_262823964.html>, consultado el 24-05-2017.

Sau Sánchez, Victoria. Reflexiones feministas para principios de siglo. Madrid: Horas y horas, 2000.

Soler Bort, Soraya. «Entrevista a Marta Galán. Marta Galán, creadora i autora contemporània». Faaan! (2015). <http://faaan.es/people_view.php?i=1506>, consultado el 23-05-2017.

Stanworth, Michelle. Reproductive technologies: gender, motherhood and medicine. New York: Polity Press, 1987. 